\title{
Cognitive behavioral group therapy for panic disorder in a general clinical setting: a prospective cohort study with 24-year follow-up
}

\section{Truls Bilet}

Helse Forde HF

\section{Thorbjørn Olsen}

Helse Forde HF

John Roger Andersen ( $\nabla$ johnra@hvl.no)

Hogskulen pa Vestlandet - Campus Forde https://orcid.org/0000-0001-6300-9086

\section{Egil W Martinsen}

Universitetet i Oslo

\section{Research article}

Keywords: anxiety, panic disorder, agoraphobia, CBT, long term follow-up, quality of life, treatment satisfaction

Posted Date: March 3rd, 2020

DOl: https://doi.org/10.21203/rs.3.rs-15823/v1

License: (9) This work is licensed under a Creative Commons Attribution 4.0 International License. Read Full License

Version of Record: A version of this preprint was published at BMC Psychiatry on May 24th, 2020. See the published version at https://doi.org/10.1186/s12888-020-02679-w. 


\section{Abstract}

Background: The long-term prognosis after cognitive behavioral therapy (CBT) in outpatient groups for panic disorder and agoraphobia is not well known. The purpose of this study was to assess long-term outcomes in terms of psychological health, health-related quality of life (HRQoL), quality of life (QoL) and treatment satisfaction after CBT for panic disorder and agoraphobia.

Methods: The sample consisted of 68 patients (61\% response rate), who were assessed at pretreatment; at the start and end of treatment; and after 3 months, after one year, and over the long term ( $M=24$ years; $S D=5.3$ ). The main outcome was the total score on the Phobic Avoidance Rating Scale (PARS-total). At long-term follow-up, HRQoL was measured with the RAND-12 questionnaire, and QoL was measured with two questions from the "Study on European Union Statistics on Income and Living Conditions". Patient experiences and treatment satisfaction were assessed by the Generic Short Patient Experiences Questionnaire. A marginal longitudinal model was applied to study the main outcome.

Results: The effect size of the change (mean change/SD of pretreatment) in the PARS-total score was $(-1.19, p<0.001)$ at the end of treatment and remained stable thereafter. A PARS-total score reduction of $50 \%$ was found in $98 \%$ of patients at the long-term follow-up. The patients' HRQoL and QoL were similar to the expected scores for the general Norwegian population. Of the patients, $95 \%$ reported high to very high satisfaction with the $\mathrm{CBT}$, and $93 \%$ reported large treatment benefits.

Conclusions: To the best of our knowledge, this study has the longest follow-up after group CBT for panic disorder and agoraphobia, showing a good prognosis in $\geq 93 \%$ of the participating patients.

\section{Introduction}

Panic disorder and agoraphobia are disabling disorders often associated with impairments in a wide range of life areas [1]. The first documented treatment for agoraphobia was exposure therapy, and later, the cognitive elements of treatment were developed. The combined form of treatment including both exposure and cognitive therapy was labeled cognitive behavioral therapy (CBT), which is increasingly viewed as the treatment of choice [2]. Antidepressant medication use is well documented [3], and there is also empirical evidence for less traditional forms of treatment, such as physical exercise [4].

Several randomized controlled trials have shown good effects of CBT in the treatment of panic disorder with or without agoraphobia $[2,5]$. In the majority of these studies, patients were selected with strict exclusion criteria, and therapists received specialized training. Fewer studies have been conducted in the general clinical setting, where fewer patients have been treated by therapists without specialized therapeutic competence. CBT is most often delivered individually, and most scientific studies have addressed individual CBT. Some have found that good results can also be achieved following group CBT [6], and this format may be more cost effective and feasible in the clinical setting. Nevertheless, the number of studies, especially long-term studies (> 2 years), on CBT in groups is scarce $[5,7,8]$. In two long-term studies with patients following inpatient treatment, 38 patients $(71 \%)$ were assessed 20 years 
after a combination of exposure and psychodynamic therapy [9], while $31(67 \%)$ were investigated after cognitive and guided mastery therapy [10]. The long-term outcomes were very good in both samples.

We found no long-term follow-up study of patients treated with group CBT in the general clinical setting. Moreover, a Cochrane review recommended that studies in this field include broader measures of quality of life (QoL) in addition to standard disease-specific outcomes [8]. Thus, we wanted to address these research needs by extending a prior study $(\mathrm{N}=83)$ published in 1998 [11]. In that study, group CBT was offered to patients with panic disorder belonging to the catchment area of the outpatient clinic of the Central Hospital of Førde in Western Norway, with a rural population of 35,000 people. In general, the patients improved during treatment and maintained those gains at one-year follow-up.

The principal aim of the current study was to investigate the long-term trajectories of outcomes in panic disorder following outpatient CBT in groups in a general clinical setting by extending the 1998 sample and performing a long-term follow-up. The secondary aims were to investigate these patients' long-term health-related quality of life (HRQoL) and QoL compared to those of the average general Norwegian population and to address patient experiences and treatment satisfaction.

\section{Methods}

In this prospective naturalistic study, assessments were carried out by personal interviews at pretreatment, at the first and last treatment sessions, and at the 3-month, 1-year, and 24-year follow-up. The study was approved by the Regional Committee for Medical Research Ethics in Western Norway (REK) and is registered in the REK archive (reference number: 2016/2693) [12]. Patients were recruited from a regional outpatient clinic serving a catchment area of approximately 35000 people referred from doctors in primary care or somatic departments. The treatment team received all referrals with a probable diagnosis of panic disorder. Those who met the DSM-III-R criteria for panic disorder with or without agoraphobia and did not meet the criteria for psychotic or posttraumatic stress disorders were offered $\mathrm{CBT}$ in a group format.

\section{Sample}

Of the 183 eligible patients who received treatment in the period 1989-2008, we were not able to trace the addresses of 63 patients (34\%), while $8(5 \%)$ were deceased. Thus, we invited 112 patients to participate. Of these, $2(1 \%)$ did not want to participate, 9 (5\%) wanted to participate but were unable for different reasons, and $32(17 \%)$ did not respond. The final sample consisted of 68 patients, yielding a response rate of $61 \%$, and they met with the therapists at the hospital. The average follow-up time since treatment was 23.8 years (SD, 5.4), ranging from 12 to 31 years. The participant characteristics at the start of treatment are presented in table 1.

\section{Treatment program}


Treatment was delivered in groups of 6 to 10 participants. The groups met each week for 11 four-hour sessions. The families or significant others were invited to one of the sessions. All group sessions were conducted by the same social worker (TO) assisted by various therapists who were either registered psychiatric nurses or registrars (TB and others). The patients in each group had two lectures on anxiety disorders and their treatment by EWM, who also supervised the therapists weekly. At the pretreatment stage, the patients were given a brief outline of the treatment explaining the rationale for exposure and cognitive restructuring. All patients who met the criteria for major depression during the pretreatment visit were offered antidepressants. Benzodiazepines were tapered and stopped within the first weeks of treatment. Patients were encouraged not to use alcohol while in therapy.

Initial sessions were devoted to psychoeducation with special emphasis on the connections between perceived threat, somatic symptoms of arousal, automatic thoughts, and anxious feelings. The physiological symptoms of sympathetic activation were examined in detail, as were feelings of disaster and catastrophic interpretations of somatic symptoms. The patients were assisted in identifying their own vicious cycles of symptoms, thoughts, and feelings and learned to rate their anxiety on a 0-10 scale. The patients were repeatedly encouraged to use diaries for recording anxiety ratings, noting daily homework assignments, discussing dysfunctional thoughts, and personally monitoring the gains made in therapy [13].

The positive benefits of regular physical activity were emphasized, and the ways in which physical activity influences health in general and anxiety specifically were explained. The patients were encouraged to implement a life-long habit of walking at least 30 minutes daily or undertaking other physical activities of their choice.

Group sessions consisted of four modules:

1. Review of homework, including anxiety ratings during exposure, and discussion of somatic symptoms, dysfunctional thoughts, and coping strategies.

2. Planning, performing, and reviewing the present day's individual in vivo exposure at downtown locations, such as attending public offices, riding the omnibus, shopping, walking the streets, or going to a café.

3. Review of the progress made during the exposure and recapitulation of cognitive theory.

4. Assignment of daily homework for the week to come

\section{Measures}

The main outcome is based on the Phobic Avoidance Rating Scale (PARS), an observer-rated scale that measures the degree of avoidance. Each item is scored on a 5-point scale where 0 represents no avoidance and 4 indicates total avoidance of the situation in question [14]. We defined a 50\% reduction in the PARS-total score as the primary indicator of a substantial response to treatment. Reduced avoidance of this magnitude is readily recognized as clinically significant by both the patient and therapist. 
Level of depression was assessed by the Beck Depression Inventory (BDI) [15], the degree of catastrophic interpretations of somatic symptoms by the Body Sensations Questionnaire (BSQ) [16], the fear of fear by the Agoraphobic Cognitions Questionnaire (ACQ)[16] and Agoraphobic Cognitions Scale (ACS) [17], and the degree of phobic avoidance by the Mobility Inventory for Agoraphobia (MIA)[18], with subscales for avoidance both alone and accompanied by others.

HRQoL, a multidimensional construct encompassing physical, psychological and social dimensions of health [19], was measured with the RAND-12 questionnaire, which covers 12 dimensions of functioning and well-being [20]. The RAND-12 has two summary scores: the physical component summary (PCS) and mental component summary (MCS). To calculate the summary scores, we applied a formula allowing the PCS and MCS to be freely correlated [20]. Higher PCS and MCS represent better scores. RAND-12 scores from the general population were obtained from the Norwegian Survey on Living Conditions in $2002(\mathrm{~N}=$ 5396) [21].

QoL, a global construct encompassing an overall assessment of well-being or life satisfaction [19], was assessed by two questions: (1) Life satisfaction: "Overall, how satisfied are you with your life nowadays (where zero is not at all satisfied and 10 is completely satisfied)?" (2) Life meaning: "Overall, to what extent do you feel that the things you do in your life are worthwhile (where zero is not at all worthwhile and 10 is completely worthwhile)?" QoL scores from the general population were obtained from the Norwegian part of the European Union Statistics on Income and Living Conditions (EU-SILC Survey) in $2017(\mathrm{~N}=6168)[21]$.

Patient experiences and treatment satisfaction were assessed by the Generic Short Patient Experiences Questionnaire (GS-PEQ), which consists of ten generic core questions that cover the essential dimensions of users' experiences with a range of specialist health care services [22]. The ten GS-PEQ item scores are intended to be used as single indicators for each of the ten specific content areas.

HRQoL, QoL and patient experiences were assessed only at long-term follow-up.

\section{Statistics}

Data are presented as frequencies or percentages and as means and standard deviations or $95 \%$ confidence intervals. Exact two-sided $p$-values are reported. Longitudinal marginal models with an unstructured covariance structure were used in analyses of change, with time as a fixed categorical effect. This method handles missing y-data by estimating outcomes based on all available data. The length of time since starting treatment was not correlated with long-term PARS-total scores $(r=0.06, p=$ 0.642). Thus, we coded all long-term data (ranging from 12 to 31 years) into one category. The trajectories of the PARS-total score during the first year of follow-up for long-term participants versus nonlong-term participants were displayed, and the interaction effect of time* group was tested. Age- and gender-adjusted comparisons of generic health status and QoL between the patient group and the general population were conducted with a one-sample t-test. Effect sizes of changes over time were calculated by using change scores from the longitudinal marginal models divided by the crude standard 
deviations at the start of treatment. Effect sizes for score differences in the patient group compared to the general population were calculated by using difference scores divided by the standard deviations in the patient group. Effect sizes were interpreted according to the following criteria: trivial $(<0.2)$, small $(0.2$ to $<0.5)$, moderate $(0.5$ to $<0.8 S D)$, and large $(\geq 0.8)$ [23]. The statistical analyses were conducted using SPSS, version 25.0 (SPSS Inc., Chicago, USA).

\section{Results}

The PARS score was stable from pretreatment to the start of treatment. The PARS-total score improved during treatment $(p<0.001)$ (Table 2-3). The effect size was large at the end of treatment and remained stable thereafter. A reduction $50 \%$ in the PARS-total score was found in $82 \%$ of the patients by the end of treatment and in $98 \%$ of patients by the 24 -year follow-up. All secondary outcomes also improved over time (Table 2; $p<0.001$ for all). The standard deviations for all scores decreased over time, indicating that the response to treatment was general. There were no significant differences between the patients who were assessed at the 24-year follow-up and the other patients in terms of their PARS-total trajectories over time $(p=0.647)$ (Figure 1).

The patients' HRQoL and QoL 24 years after CBT were similar to the expected scores in the general population after adjustment for age and gender (Table 5). Details on patient experiences and treatment satisfaction at the 24-year follow-up are presented in table 4 . The patients had high ratings on all items, with 95\% reporting high to very high satisfaction with the CBT and 93\% reporting large benefits.

\section{Discussion}

To the best of our knowledge, this study has the longest follow-up after group CBT for panic disorder and agoraphobia. The effect size for clinical treatment was large at the end of treatment and remained stable thereafter. A $50 \%$ reduction in the PARS-total score was found in $98 \%$ of patients at the long-term followup, and $93 \%$ of patients were satisfied with the outcomes. The patients' HRQoL and QoL were similar to the expected scores for the general Norwegian population.

Our results correspond well with previous shorter-term studies on the treatment of panic disorder and agoraphobia $[2,4]$ and with the few studies reporting long-term outcomes $[9,10]$. Systematic exposure treatment and cognitive therapy yield substantial and lasting therapeutic gains, and these results can be achieved in the general clinical setting. Thus, the good results following individual CBT seem to be achieved by group CBT as well. This format is suitable for training new therapists, who can learn the method by working as co-therapists with more experienced professionals.

The main strength of this study is its length of follow-up. Moreover, the study was conducted in the general clinical setting, had few exclusion criteria and included participants with multiple comorbidities. Thus, the results are generalizable to the general clinical setting. Furthermore, we had a broad set of validated measures encapsulating mental health, HRQoL, QoL, and patient experiences and treatment 
satisfaction. The study's main limitations are its observational design, and we do not know the long-term prognosis of the $39 \%$ of patients who did not participate in the long-term follow-up. Loss of patients is also observed in other studies with a very long follow-up period $[9,10]$. Patients may have chosen not to participate in the long-term follow-up because they were doing well and perceived their attendance as unnecessary, because they were doing poorly and did not want further contact, or because they had other reasons unrelated to the study outcomes. However, it is reassuring that the PARS-total trajectories during the first year after treatment were similar in long-term and other participants.

In conclusion, our study suggests that CBT in groups is feasible and that the therapeutic gains last for a very long period of time. This finding is good news for a common mental health problem. However, further studies are needed to establish a robust body of evidence on this matter.

\section{Declarations}

\section{Ethics approval and consent to participate}

The study was approved by the Regional Committee for Medical Research Ethics in Western Norway (reference number: 2016/2693). The participants provided informed written consent to participate in this study.

\section{Consent for publication}

Not applicable.

\section{Availability of data and materials}

The dataset generated during this study is not publicly available, as the patient consent and approval from the Regional Committee for Medical and Health Research Ethics prevent us from sharing individual patient-level data in public repositories. However, the data are available upon reasonable request from the corresponding author.

\section{Competing interests}

The authors declare that they have no competing interests.

\section{Funding}

This work was supported by internal grants from Førde Hospital Trust, Førde, Norway.

\section{Author contributions}

All authors designed the study and drafted, edited and reviewed the manuscript. TB and TO collected and coded the data. JRA conducted the statistical analysis. All authors read and approved the final version of the manuscript. 
Acknowledgments

We would like to thank Karl Ove Hufthammer, (Department of Research and Development, Haukeland University Hospital, Bergen, Norway) for supporting the statistical analyses. We also thanks Kristen Hagen (OCD-Team, Molde Hospital, Molde, Norway) for providing useful comments on the manuscript.

\section{References}

1. Barrera TL, Norton PJ: Quality of life impairment in generalized anxiety disorder, social phobia, and panic disorder. J Anxiety Disord 2009, 23(8):1086-1090.

2. van Dis EAM, van Veen SC, Hagenaars MA, Batelaan NM, Bockting CLH, van Den Heuvel RM, Cuijpers P, Engelhard IM: Long-term Outcomes of Cognitive Behavioral Therapy for Anxiety-Related Disorders: A Systematic Review and Meta-analysis. JAMA psychiatry 2019.

3. Nathan PE, Gorman JM: A guide to treatments that work, 4th edition.. edn; 2015.

4. Hovland A, Nordhus IH, Sjobo T, Gjestad BA, Birknes B, Martinsen EW, Torsheim T, Pallesen S: Comparing physical exercise in groups to group cognitive behaviour therapy for the treatment of panic disorder in a randomized controlled trial. Behav Cogn Psychother 2013, 41(4):408-432.

5. Pompoli A, Furukawa TA, Imai H, Tajika A, Efthimiou O, Salanti G: Psychological therapies for panic disorder with or without agoraphobia in adults: a networkmeta-analysis. Cochrane Db Syst Rev 2016(4).

6. Prats E, Dominguez E, Rosado S, Pailhez G, Bulbena A, Fullana MA: Effectiveness of cognitivebehavioral group therapy for panic disorder in a specialized unit. Actas Esp Psiquiatri 2014, 42(4):176-184.

7. von Brachel R, Hirschfeld G, Berner A, Willutzki U, Teismann T, Cwik J, Velten J, Schulte D, Margraf J: Long-Term Effectiveness of Cognitive Behavioral Therapy in Routine Outpatient Care: A 5-to 20-Year Follow-Up Study. Psychotherapy and psychosomatics 2019, 88(4):225-235.

8. Imai H, Tajika A, Chen P, Pompoli A, Furukawa TA: Psychological therapies versus pharmacological interventions for panic disorder with or without agoraphobia in adults. Cochrane Db Syst Rev 2016(10).

9. Hoffart A, Hedley LM, Svanoe K, Langkaas TF, Sexton H: Agoraphobia With and Without Panic Disorder A 20-Year Follow-up of Integrated Exposure and Psychodynamic Therapy. Journal of Nervous and Mental Disease 2016, 204(2):100-107.

10. Hoffart A, Hedley LM, Svanoe K, Sexton H: Cognitive and Guided Mastery Therapies for Panic Disorder with Agoraphobia: 18-Year Long-Term Outcome and Predictors of Long-Term Change. Clin Psychol Psychother 2016, 23(1):1-13.

11. Martinsen EW, Olsen T, Tonset E, Nyland KE, Aarre TF: Cognitive-behavioral group therapy for panic disorder in the general clinical setting: A naturalistic study with 1-year follow-up. J Clin Psychiat 1998, 59(8):437-442. 
12. Langtidsforløpet ved panikklidelse

[https://helseforskning.etikkom.no/prosjekterirek/prosjektregister/prosjekt?

p_document_id=710071\&p_parent_id=729946\&_ikbLanguageCode $=n]$

13. Clark DM: A Cognitive Approach to Panic. Behaviour research and therapy 1986, 24(4):461-470.

14. Hoffart A, Friis S, Martinsen EW: The Phobic Avoidance Rating-Scale - a Psychometric Evaluation of an Interview-Based Scale. Psychiat Dev 1989, 7(1):71-81.

15. Beck AT, Steer RA, Ball R, Ranieri WF: Comparison of Beck Depression Inventories-IA and -II in psychiatric outpatients. Journal of personality assessment 1996, 67(3):588-597.

16. Chambless DL, Caputo GC, Bright P, Gallagher R: Assessment of Fear of Fear in Agoraphobics - the Body Sensations Questionnaire and the Agoraphobic Cognitions Questionnaire. J Consult Clin Psych 1984, 52(6):1090-1097.

17. Hoffart A, Friis S, Martinsen EW: Assessment of Fear of Fear among Agoraphobic Patients - the Agoraphobic Cognitions Scale. J Psychopathol Behav 1992, 14(2):175-187.

18. Chambless DL, Caputo GC, Jasin SE, Gracely EJ, Williams C: The Mobility Inventory for Agoraphobia. Behaviour research and therapy 1985, 23(1):35-44.

19. Cramer JA, Spilker B: Quality of life and pharmacoeconomics an introduction. Philadelphia: Lippincott-Raven; 1998.

20. Farivar SS, Cunningham WE, Hays RD: Correlated physical and mental health summary scores for the SF-36 and SF-12 Health Survey, V.I. Health Qual Life Outcomes 2007, 5:54.

21. Norwegian Surveys on Living Conditions [https://nsd.no/nsddata/serier/levekaarundersokelser.html]

22. Sjetne IS, Bjertnaes OA, Olsen RV, Iversen HH, Bukholm G: The Generic Short Patient Experiences Questionnaire (GS-PEQ): identification of core items from a survey in Norway. BMC health services research 2011, 11.

23. Cohen J: Statistical Power Analysis for the Behavioral Sciences., 1 edn. New York: Academic Press; 1988.

\section{Tables}

Table 1. Pretreatment patient characteristics 


\begin{tabular}{|c|c|c|}
\hline Characteristics & $\begin{array}{l}\text { Long-term participants } \\
\qquad(\mathrm{n}=68)\end{array}$ & Non-long-term participants $(\mathrm{n}=114)$ \\
\hline Age, years, mean (SD) & $34.8(10.3)$ & $37.6(10.0)$ \\
\hline Females, \% & 73.5 & 69.1 \\
\hline \multicolumn{3}{|l|}{ Marital status, $\%$} \\
\hline Married or cohabiting & 69.1 & 76.3 \\
\hline Divorced/widowed & 11.8 & 6.1 \\
\hline Single & 19.1 & 17.6 \\
\hline \multicolumn{3}{|l|}{ Occupation, \% } \\
\hline Employed & 68.7 & 64.0 \\
\hline Receiving social security benefits & 13.5 & 18.5 \\
\hline Other, not employed & 17.7 & 17.5 \\
\hline Age at onset of anxiety disorder, mean (SD) & $28.0(9.0)$ & $30.6(10.4)$ \\
\hline Years of duration of anxiety disorder, mean (SD) & $6.8(7.4)$ & $6.8(8.0)$ \\
\hline Previous psychiatric treatment, \% & 48.5 & 51.8 \\
\hline \multicolumn{3}{|l|}{ DSM-III-R Axis diagnosis, Panic disorder, \% } \\
\hline With agoraphobia & 77.9 & 78.1 \\
\hline Without Agoraphobia & 22.1 & 21.9 \\
\hline
\end{tabular}

Note: SD: standard deviation.

Table 2. Means scores based on marginal models with crude standard deviations before and after cognitive behavioral group therapy

\begin{tabular}{|c|c|c|c|c|c|c|}
\hline Rating scale & $\begin{array}{l}\text { Pretreatment } \\
\qquad(\mathrm{n}=139)\end{array}$ & $\begin{array}{l}\text { Start of treatment } \\
\qquad(\mathrm{n}=173)\end{array}$ & $\begin{array}{l}\text { End of treatment } \\
\qquad(\mathrm{n}=170)\end{array}$ & $\begin{array}{l}\text { 3-month follow-up } \\
\qquad(\mathrm{n}=142)\end{array}$ & $\begin{array}{l}\text { 1-year follow-up } \\
\qquad(\mathrm{n}=118)\end{array}$ & $\begin{array}{l}\text { 24-year follow-up } \\
\qquad(\mathrm{n}=68)\end{array}$ \\
\hline PARS-tot. & $1.5(0.9)$ & $1.5(0.9)$ & $0.4(0.5)$ & $0.4(0.7)$ & $0.4(0.7)$ & $0.3(0.5)$ \\
\hline PARS-sep. & $1.6(1.0)$ & $1.5(1.0)$ & $0.4(0.5)$ & $0.3(0.6)$ & $0.4(0.7)$ & $0.3(0.5)$ \\
\hline PARS-soc. & $1.5(1.1)$ & $1.5(1.1)$ & $0.4(0.7)$ & $0.5(0.8)$ & $0.5(0.8)$ & $0.3(0.5)$ \\
\hline MI-AAC & $50.5(20.1)$ & 50.6 (19.3) & $34.4(11.0)$ & 33.7 (10.8) & $33.3(13.1)$ & $31.4(7.2)$ \\
\hline MI-AAL & $69.2(25.0)$ & $67.8(27.2)$ & $42.3(15.8)$ & $41.2(15.6)$ & 40.5 (19.4) & 37.5 (14.5) \\
\hline ACQ & $37.0(10.1)$ & $37.8(11.1)$ & $25.9(9.0)$ & $24.1(9.0)$ & 22.9 (7.6) & 21.8 (7.7) \\
\hline BSQ & 47.3 (13.6) & $46.6(12.4)$ & $29.9(10.5)$ & $28.9(11.1)$ & $28.4(12.2)$ & $28.2(11.5)$ \\
\hline BDI & $16.7(8.2)$ & 15.5 (8.6) & $7.4(6.8)$ & $7.3(8.1)$ & $6.5(8.1)$ & $5.9(5.9)$ \\
\hline
\end{tabular}

Abbreviations: ACQ = Anxiety Cognitions Questionnaire; ACS = Agoraphobic Cognitions Scale; BDI = Beck Depression Inventory; BSQ = Body Sensation Questionnaire; MI-ACC = Mobility Inventory for Agoraphobia, Avoidance Accompanied; MI-ALL = Mobility Inventory for Agoraphobia, Avoidance Alone; PARS = Phobic Avoidance Rating Scale; PARS-sep = PARS Separation Subscale; PARS-soc = PARS Social Subscale. P-values were $<0.001$ for the effect of time on all scales. 
Table 3. Primary outcome: changes over time in the Phobic Avoidance Rating Scale (total score)

\begin{tabular}{|l|c|c|}
\hline Assessments & Mean change (95\% CI) & Effect size \\
\hline Pretreatment & Ref. & Ref. \\
\hline Treatment start & $0.01(-0.12,0.14)$ & -0.01 \\
\hline End of treatment & $-1.10(-1.26,-0.95)$ & -1.19 \\
\hline 3-month follow-up & $-1.08(-1.23,-0.92)$ & -1.17 \\
\hline 1-year follow-up & $-1.08(-1.24,-0.93)$ & -1.17 \\
\hline 24-year follow-up & $-1.22(-1.38,-1.07)$ & -1.32 \\
\hline
\end{tabular}

Note: The effect size was calculated by dividing the change scores by the pretreatment standard deviation $(\mathrm{SD}=0.925)$. P-value for the overall effect of time $<0.001$.

Table 4. The Generic Short Patient Experiences Questionnaire scores at the 24-year follow-up

\begin{tabular}{|c|c|c|c|c|c|c|}
\hline Items & $\begin{array}{l}\text { Not at } \\
\text { all }\end{array}$ & $\begin{array}{l}\text { To a small } \\
\text { extent }\end{array}$ & $\begin{array}{c}\text { To a } \\
\text { moderate } \\
\text { extent }\end{array}$ & $\begin{array}{l}\text { To a large } \\
\text { extent }\end{array}$ & $\begin{array}{l}\text { To a very } \\
\text { large extent }\end{array}$ & $\begin{array}{c}\text { Not } \\
\text { applicable }\end{array}$ \\
\hline $\begin{array}{l}\text { Did the clinicians talk to you in a way that was easy to } \\
\text { understand? }\end{array}$ & 0 & 0 & 1 & 26 & 31 & 0 \\
\hline $\begin{array}{l}\text { Do you have confidence in the clinicians' professional } \\
\text { competence? }\end{array}$ & 0 & 0 & 1 & 14 & 43 & 0 \\
\hline $\begin{array}{l}\text { Did you get sufficient information about your diagnosis/your } \\
\text { afflictions? }\end{array}$ & 0 & 0 & 5 & 26 & 27 & 0 \\
\hline $\begin{array}{l}\text { Did you perceive the treatment you received as suited to your } \\
\text { situation? }\end{array}$ & 0 & 0 & 4 & 21 & 33 & 0 \\
\hline Were you involved in any decisions regarding your treatment? & 0 & 2 & 6 & 21 & 28 & 1 \\
\hline Did you perceive the institution's work as well organized? & 0 & 0 & 1 & 24 & 31 & 2 \\
\hline $\begin{array}{l}\text { Do you believe that you were in any way given the wrong } \\
\text { treatment (according to your own judgment)? }\end{array}$ & 49 & 4 & 1 & 1 & 0 & 3 \\
\hline \multirow{2}{*}{$\begin{array}{l}\text { Overall, were the help and treatment you received at the } \\
\text { institution satisfactory? }\end{array}$} & 1 & 0 & 1 & 17 & 36 & 1 \\
\hline & No & $\begin{array}{c}\text { Yes, but } \\
\text { not so long }\end{array}$ & $\begin{array}{l}\text { Yes, quite } \\
\text { long }\end{array}$ & $\begin{array}{l}\text { Yes, much } \\
\text { too long }\end{array}$ & - & $\begin{array}{c}\text { Not } \\
\text { applicable }\end{array}$ \\
\hline \multirow{2}{*}{$\begin{array}{l}\text { Did you have to wait before you were admitted for services at } \\
\text { the institution? }\end{array}$} & 27 & 25 & 3 & 1 & & 0 \\
\hline & $\begin{array}{c}\text { No } \\
\text { benefit }\end{array}$ & $\begin{array}{c}\text { Small } \\
\text { benefit }\end{array}$ & $\begin{array}{c}\text { Some } \\
\text { benefit }\end{array}$ & $\begin{array}{l}\text { Great } \\
\text { benefit }\end{array}$ & $\begin{array}{c}\text { Huge } \\
\text { benefit }\end{array}$ & $\begin{array}{c}\text { Not } \\
\text { applicable }\end{array}$ \\
\hline $\begin{array}{l}\text { Overall, what benefit have you had from the care at the } \\
\text { institution? }\end{array}$ & 0 & 1 & 3 & 20 & 33 & 0 \\
\hline
\end{tabular}

Note: The results are presented as the distribution in scores according to the crude numbers of patients on the different answer categories (number of patients ranging from 56 to 58). 
Table 5. General health status and quality of life in the patient group at 24-year follow-up compared to the general Norwegian population

\begin{tabular}{|l|c|c|c|c|}
\hline Outcomes & $\begin{array}{c}\text { Patient } \\
\text { mean (SD) }\end{array}$ & $\begin{array}{c}\text { General population } \\
\text { mean }\end{array}$ & P-value & Effect size \\
\hline Physical health status & $49.5(9.4)$ & 49.4 & 0.923 & 0.1 \\
\hline Mental health status & $48.8(11.4)$ & 51.1 & 0.104 & -0.3 \\
\hline Life satisfaction & $8.0(2.1)$ & 8.1 & 0.699 & -0.1 \\
\hline Life meaning & $8.3(1.7)$ & 8.1 & 0.413 & 0.2 \\
\hline
\end{tabular}

Note: Differences in outcomes are adjusted for age and gender. Effect size = mean difference in scores between patients and the general population divided by the standard deviation of the patient scores.

\section{Figures}

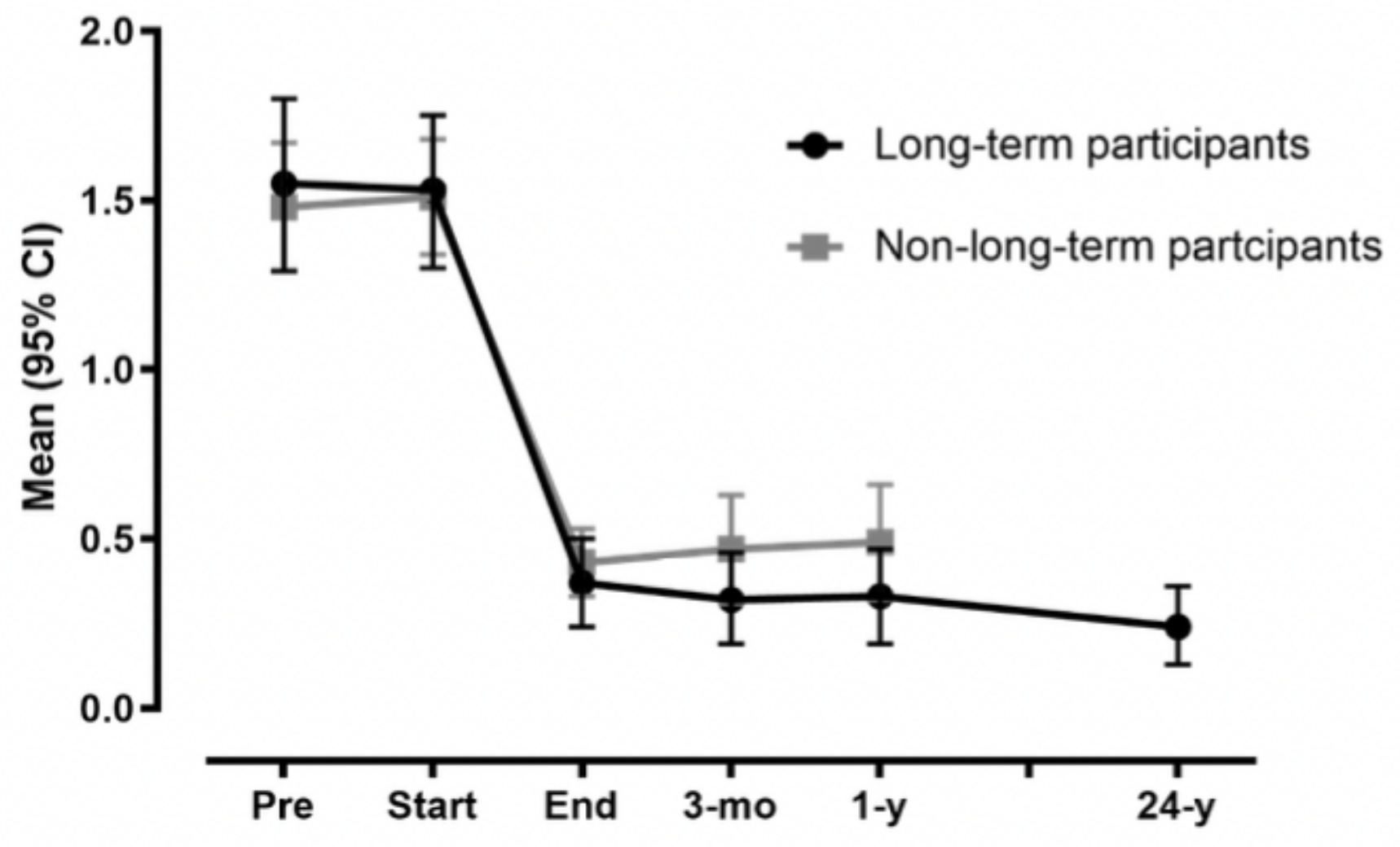

Figure 1

Mean total Phobic Avoidance Rating Scale trajectories over time in patients attending the 24-year followup (long-term participants) versus the other patients (non-long-term participants). Pre: pretreatment, Start: start of treatment, End: end of treatment, 3-mo: 3-month follow-up, 1 y: 1-year follow-up, 24 y: 24-year follow-up. P-value for time * group interaction $=0.647$. 